\title{
On measures of association for multiple- cause mortality: Do we need more measures?
}

\author{
Sulaiman Bah \\ Department of Health Information Management and Technology \\ College of Applied Medical Sciences \\ University of Dammam (Saudi Arabia) \\ sbah@ud.edu.sa
}

M. Mahibbur Rahman

Department of Statistics and Demography

University of Swaziland, Kwaluseni (Swaziland)

\begin{abstract}
More than 70 measures exist for analyzing the binary association of a $2 \times 2$ contingency table. Of these, only five are used in multiple-cause mortality. The aim of the paper is to answer the question of whether these measures are adequate. Building on comparative reviews of measures of association, the paper identifies three additional measures as suitable candidates. These additional measures, together with the five existing ones, are assessed for their theoretical utility based on seven criteria laid out in the paper. Subsequently, the same measures are applied to South African multiple-cause data that comprises over four million records. The multiple-cause software Cause_limp v1.1 was used to extract the data for the cell entries of the $2 \times 2$ contingency table, with diabetes as a multiple-cause and cardiac arrest as a co-morbid condition. The paper concludes that existing measures of multiple-cause mortality need to be supplemented with other measures, in particular the Positive Matching Index (PMI). This measure is found to satisfy all the criteria laid out, and produces the most consistent results among all the measures compared.
\end{abstract}

Keywords: measures of association, multiple-cause mortality, contingency table.

\section{Résumé}

Il existe plus de 70 mesures pour analyser les associations binaires de la méthode croisée 2×2. De ces mesures, seulement cinq sont utilisées dans les cas de cause complexe de mortalité. Le but de l'article est de répondre à la question de savoir si ces mesures sont adéquates. En renforçant les critiques comparatives des mesures d'association, l'article identifie trois mesures additionnelles pouvant convenir. Ajoutées aux cinq mesures qui existent déjà, ces mesures additionnelles sont évaluées à la lumière de leur utilité théorique basée sur sept critères énoncés dans l'article. Par la suite, les mêmes mesures sont appliquées aux données relatives aux causes complexes de mortalité en Afrique du Sud, comprenant plus de quatre millions de dossiers. On a utilisé le logiciel de cause complexe Cause_limp v1.1 pour extraire les données des entrées dans les cellules de la table croisée 2x2 avec le diabète comme cause complexe et l'arrêt cardiaque comme comorbidité. L'article conclut que d'autres mesures, tout particulièrement l'indice homologue positif (Positive Matching Index (PMI)) doivent être ajoutées aux mesures existantes de causes complexes de mortalité. On a constaté que cette mesure satisfaisait à tous les critères énoncés et produisait les résultats les plus constants de toutes les mesures ayant fait l'objet de la comparaison.

Mots-clés : mesures d'association; cause complexe; mortalité; table croisée. 


\section{Introduction}

An extant problem in the analysis of multiple-cause mortality is to study the joint occurrence of two different causes of death. From the joint occurrence, different patterns of association can be studied, and these have implications for understanding causation, as well as assessing the quality of coding. The starting point in this kind of analysis is summarization of the data in a 2x2 binary table. The two columns show the presence or absence of a disease of interest, and the rows would show the presence or absence of a co-morbid condition of interest. Once this has been done, analysis of the contingency table could then draw upon the rich body of knowledge on indices of association (similarity) to summarize the tables. Surprisingly, this approach has been lacking in the literature. The different measures used in multiple-cause mortality have been summarized in Bah and Mahibur Rahman (2009). The paper identifies ten measures of association used in multiple-cause mortality research. Of these measures, only five can be derived from a $2 \times 2$ contingency table. But based on $2 \times 2$ contingency table, there are over 70 indices of similarity coming from an active area of multidisciplinary research spanning a period of over a century (Choi et al. 2010). The paper draws upon this rich literature to select some indices with potential relevance to multiple causemortality analysis. Some of the measures are then applied to real data. The methods and materials used for the application are described, followed by a description of the results. The results are discussed in light of the question posed in the paper, and finally a conclusion is reached.

\section{Methods and materials}

This section is divided into two parts; one part deals with the theoretical assessment of measures of association, with the aim of arriving at ideal measure(s) of association for multiple-cause mortality. The second part deals with the application of the reviewed measures to real data, with the aim of empirically reconfirming the appropriateness of the chosen measure(s) of association.

\section{Theoretical assessment}

The general framework used for the measures of association is the $2 \times 2$ contingency table shown in Table 1.

In multiple causes of death, two co-morbid causes can be found together in a record (a) or can both be absent from it (d). Further, a record can contain either of the two co-morbid causes (b or c). Ideally, the recorded causes of death should depend on the actual causes present at the time of death. In such a situation, the values of the cells a, b, c, and d would be accurate and objective. In reality,

Table 1. General framework for computing measures of association from a $2 \times 2$ contingency table.

\begin{tabular}{lccc}
\hline & Disease Present & Disease Absent & Total \\
\hline Co-morbid Present & $a$ & $b$ & $a+b$ \\
Co-morbid Absent & $c$ & $d$ & $c+d$ \\
\hline Total & $a+c$ & $b+d$ & $N$ \\
\hline
\end{tabular}


recorded causes of death depend on several factors. One important factor is the place of death. More information is available for deaths taking place in hospitals than those taking place out of hospitals or after discharge. Part of the reason for this is that deaths taking place in hospitals have been attended by physicians and hence are more likely to have more complete medical charts and hence more information on causes of death than deaths taking place out of hospitals (Wall et al. 2005). Another factor pertains to the certification practices of physicians. This is partly related to the training of physicians and the "acceptability" among physicians of recording certain causes of death (Speizer et al. 1977). Yet another factor has to do with coding practice in the statistical office. Variation in coding practices, for policy reasons or otherwise, could lead to some discrepancies between actual and recorded causes of death (Jougla et al. 2008). For these and other reasons, the $2 \times 2$ matrix in multiple-cause analysis reflects both the actual number of deaths due to the different co-morbid combinations as well as other factors related to the certification and coding processes. This makes analysis of association in multiplecause data slightly different from that in other disciplines, such as ecology, for example. Taking these factors into account, we propose below criteria for a useful measure of association for multiple-cause mortality. In proposing the criteria, we draw upon existing work in the area by Janson and Vegelius (1981), Tulloss (1997), and Warrens (2008a, 2008b). We review their criteria in the light of their relevance to multiple-cause analysis. Relevant ones are accepted and/or modified, and irrelevant ones are dropped from the selected criteria.

The proposed criteria for an ideal index of multiple-cause association are as follows:

- The ideal measure of association $M$ should have a minimum of zero (0) when there is no occurrence of the two disease conditions together (Janson and Vegelius 1981; Tulloss 1997);

- The ideal measure of association $M$ should have a maximum value of unity (1) when the two disease conditions are always together (Janson and Vegelius 1981; Tulloss 1997);

- Since theoretically each value of the $2 \times 2$ matrix could be zero, the multiplecause index of association $M$ should either be free of indeterminacies or should be defined in such as way that indeterminacies are avoided (Warrens 2008a);

- The ideal measure of association $M$ should not include negative matches $d$ (Janson and Vegelius 1981);

- An ideal measure of association $M$ should be free of "aliasing." Different value combinations of cell entries $b$ and $c$ should not give the same value of the index (Tulloss 1997);

- The measure of association $M$ monotonically increases with the positive match $a$ when the number of mentions of one morbid condition $(a+c)$ and number of mentions of the other morbid condition $(a+b)$ remain unchanged (adapted from Piatetsky-Shapiro 1991);

- The measure of association $M$ monotonically decreases with number of mentions of one morbid condition $(a+c)$ [or $(a+b)]$ when the cell entries $a$ and $(a+b)[$ or $(a+c)]$ remain unchanged (adapted from Piatetsky-Shapiro 1991). 
We apply these seven criteria to the five existing association measures of multiple-cause mortality as described in Bah and Mahibur Rahman (2009). These are given in Table 2. We add to these the "best" recommended measures according to the reviews summarised in Appendix 1. The TSI has not been included, as it has been superseded by the PMI. These measures are shown in Table 3.

Table 2. Association measures used in multiple-cause mortality.

\begin{tabular}{lrl}
\hline \multicolumn{1}{c}{ Measure } & \multicolumn{1}{c}{ Definition } & Source from the multiple-cause literature \\
\hline Yule's Q & $M 1=\frac{a d-b c}{a d+b c}$ & Chamblee (1982) \\
Forbes' coefficient & $M 3=\frac{N a}{(a+c)(a+b)}$ & Israel et al. (1986) \\
Odds ratio & $M 4=\frac{a(c+d)}{c(a+b)}$ & Wilkins et al. (1997) \\
Relative risk & $M 5=\frac{a(b+d)}{b(a+c)}$ & Mannino et al. (1998) \\
Wise and Sorvillo ratio & $M$ Wise and Sorvillo (2002) &
\end{tabular}

Table 3. Selected association measures used in other fields.

\begin{tabular}{|c|c|c|}
\hline Measure & Definition & Source \\
\hline Yule's Y & $M 6=\frac{\sqrt{a d}-\sqrt{b c}}{\sqrt{a d}+\sqrt{b c}}$ & Yule (1912) \\
\hline Digby's H & $M 7=\frac{a d^{3 / 4}-b c^{3 / 4}}{a d^{3 / 4}+b c^{3 / 4}}$ & Digby (1983) \\
\hline \multirow[t]{2}{*}{$\begin{array}{l}\text { Positive Matching Index } \\
\text { (PMI) }\end{array}$} & M8 $=\frac{a}{|b-c|} \ln \left(\frac{a+\max (b, c)}{a+\min (b, c)}\right)$ when $b \neq c$ & Dos Santos et al (2010) \\
\hline & M8 $=\frac{a}{(a+b)}$ when $b=c$ & \\
\hline
\end{tabular}

\section{Application to real data}

The data used in the study is the national data on causes of death in South Africa and covers the period 1997 to 2005. The data for this study period consist of a little over 4.2 million records. The variables used in the analysis are the following: age, sex, all the multiple causes listed on the certificate (five causes in all), the underlying cause of death, the province of residence, and the province of death. The first stage of the analysis of the cause of death data was done using Cause_Limp v1.1, a public-domain software application for analysing South African multiple-cause data (Bah 2009). The software routinely eliminates all stillbirths and deceased cases with unknown sex before doing a sex-specific analysis. The geographic filter also allows one to specify region of residence and region of death. In this case, the analysis is restricted to those whose region of residence and of death are the same. The perspective used is that of the resident population. The software produces the contingency tables used for computing different indices of similarity.

For illustrative purposes, the disease of interest chosen is diabetes (ICD 10 codes: E10-E14) and the co-morbid condition selected is cardiac arrest (ICD 10 
code: I46). Part of the reason for choosing these causes of death is that they are not diseases that physicians would shy away from reporting if they were found to be present. In the South African context, these are not considered as disease, having any stigma attached to them, unlike a disease such as HIV.

\section{Results}

As with the section on methods and materials, this section is divided into two parts. The first part deals with the results of the theoretical assessment of the different selected measures in the light of the criteria laid out above, and the second sections deals with their practical application.

\section{Results of the theoretical assessment}

The results in Table 4 show that only the PMI has a range from 0 to 1 , and only the PMI satisfies all the seven criteria laid out above.

Table 4: Application of the criteria to selected measures of multiple-cause association.

\begin{tabular}{lcccccccc}
\hline \multicolumn{1}{c}{ Measures (M) } & Range & C1 & C2 & C3 & C4 & C5 & C6 & C7 \\
\hline Yule's Q & $-1 ; 1$ & No & Yes & Yes & No & No & Yes & Yes \\
Forbes' coefficient & $0 ; \infty$ & Yes & No & Yes & Yes & Yes & Yes & Yes \\
Odds ratio & $0 ; \infty$ & Yes & No & No & No & No & Yes & Yes \\
Relative risk & $0 ; \infty$ & Yes & No & No & No & Yes & Yes & Yes \\
Wise and Sorvillo & $0 ; \infty$ & Yes & No & No & No & Yes & Yes & Yes \\
$\quad$ ratio & $-1 ; 1$ & No & Yes & Yes & No & No & Yes & Yes \\
Yule's Y & $-1 ; 1$ & No & Yes & Yes & No & No & Yes & Yes \\
Digby's H & $0 ; 1$ & Yes & Yes & Yes & Yes & Yes & Yes & Yes \\
PMI & & & & & & & &
\end{tabular}

\section{Results of the application to real data}

The cell entries for the $2 \times 2$ table involving diabetes and cardiac arrest are shown in Table 5. The results were obtained from Cause_Limp v1.1. From these cell entries, all the selected indices of association were computed. These results are shown in Tables 6 and 7, for males and females, respectively. The same results are graphically shown in Figures $1 \mathrm{a}$ and $1 \mathrm{~b}$ for males, and in Figures $2 \mathrm{a}$ and $2 \mathrm{~b}$ for females.

The results from Table 5 show that for both males and females the number of cases with cardiac arrest as a co-morbid condition with diabetes present (a) or without diabetes (b) declined rapidly between 1997 and 2000 but remained largely stable afterwards. Not surprisingly, the increase in deaths experienced in South Africa during the 2000s is reflected in the deaths not related to cardiac arrest ( $c$ and $d$ ). With the exception of the PMI, none of the measures reviewed in the paper was able to capture this reality. Only the PMI reflected this reality, showing a decline between 1997 and 2000 and constancy afterwards. 
Table 5. Cell entries for multiple-cause mortality involving diabetes and cardiac arrest, South Africa, males and females, 1997-2005.

\begin{tabular}{ccccc|rrrr}
\hline \multirow{2}{*}{ Year } & \multicolumn{5}{c|}{ Males } & \multicolumn{4}{c}{ Females } \\
\cline { 2 - 8 } & $\mathrm{a}$ & $\mathrm{b}$ & $\mathrm{c}$ & $\mathrm{d}$ & $\mathrm{a}$ & \multicolumn{1}{c}{$\mathrm{b}$} & $\mathrm{c}$ & $\mathrm{d}$ \\
\hline 1997 & 617 & 10823 & 4249 & 163918 & 953 & 10341 & 6056 & 124413 \\
1998 & 622 & 11098 & 4961 & 187459 & 964 & 10177 & 7177 & 148236 \\
1999 & 405 & 7315 & 5224 & 199021 & 589 & 6848 & 7751 & 163518 \\
2000 & 317 & 6509 & 5772 & 212377 & 477 & 6523 & 8579 & 184616 \\
2001 & 297 & 5961 & 6086 & 231562 & 433 & 5992 & 9233 & 206179 \\
2002 & 319 & 5634 & 6625 & 250959 & 424 & 5887 & 10063 & 231154 \\
2003 & 323 & 6321 & 6905 & 276891 & 459 & 6261 & 10817 & 258189 \\
2004 & 306 & 5817 & 7205 & 284775 & 456 & 5992 & 10844 & 270750 \\
2005 & 346 & 5861 & 7523 & 291133 & 472 & 5947 & 12019 & 279678 \\
\hline
\end{tabular}

Source: Output from Cause_Limp v1.1

Table 6. Values of similarity indices for multiple-cause mortality involving diabetes and cardiac arrest, South Africa, males, 1997-2005.

\begin{tabular}{ccccccccc}
\hline Year & Yule's Q $\begin{array}{c}\text { Forbes' } \\
\text { coefficient }\end{array}$ & $\begin{array}{c}\text { Odds } \\
\text { ratio }\end{array}$ & $\begin{array}{c}\text { Relative } \\
\text { risk }\end{array}$ & $\begin{array}{c}\text { Wise and } \\
\text { Sorvillo } \\
\text { ratio }\end{array}$ & Yule's Y & $\begin{array}{c}\text { Digby's } \\
\text { H }\end{array}$ & $\begin{array}{c}\text { Positive } \\
\text { Matching } \\
\text { Index }\end{array}$ \\
\hline 1997 & 0.375 & 1.991 & 2.199 & 2.135 & 2.047 & 0.195 & 0.287 & 0.080 \\
1998 & 0.359 & 1.941 & 2.118 & 2.058 & 1.993 & 0.185 & 0.274 & 0.075 \\
1999 & 0.357 & 1.976 & 2.109 & 2.051 & 2.030 & 0.185 & 0.273 & 0.061 \\
2000 & 0.284 & 1.716 & 1.792 & 1.755 & 1.751 & 0.145 & 0.215 & 0.049 \\
2001 & 0.309 & 1.814 & 1.896 & 1.853 & 1.854 & 0.159 & 0.235 & 0.047 \\
2002 & 0.364 & 2.034 & 2.145 & 2.083 & 2.092 & 0.189 & 0.279 & 0.050 \\
2003 & 0.344 & 1.954 & 2.049 & 1.998 & 2.002 & 0.178 & 0.263 & 0.047 \\
2004 & 0.351 & 1.984 & 2.079 & 2.025 & 2.035 & 0.181 & 0.268 & 0.045 \\
2005 & 0.391 & 2.160 & 2.285 & 2.213 & 2.228 & 0.204 & 0.300 & 0.049 \\
\hline
\end{tabular}

Table 7. Values of similarity indices for multiple-cause mortality involving diabetes and cardiac arrest, South Africa, females, 1997-2005.

\begin{tabular}{ccccccccc}
\hline Year & Yule's Q & $\begin{array}{c}\text { Forbes' } \\
\text { coefficient }\end{array}$ & $\begin{array}{c}\text { Odds } \\
\text { ratio }\end{array}$ & $\begin{array}{c}\text { Relative } \\
\text { risk }\end{array}$ & $\begin{array}{c}\text { Wise and } \\
\text { Sorvillo } \\
\text { ratio }\end{array}$ & Yule's Y & $\begin{array}{c}\text { Digby's } \\
\text { H }\end{array}$ & $\begin{array}{c}\text { Positive } \\
\text { Matching } \\
\text { Index }\end{array}$ \\
\hline 1997 & 0.309 & 1.707 & 1.893 & 1.818 & 1.772 & 0.158 & 0.235 & 0.106 \\
1998 & 0.324 & 1.770 & 1.956 & 1.874 & 1.843 & 0.166 & 0.247 & 0.101 \\
1999 & 0.289 & 1.697 & 1.815 & 1.750 & 1.757 & 0.148 & 0.220 & 0.075 \\
2000 & 0.223 & 1.506 & 1.574 & 1.535 & 1.543 & 0.113 & 0.168 & 0.060 \\
2001 & 0.235 & 1.547 & 1.614 & 1.572 & 1.586 & 0.119 & 0.178 & 0.055 \\
2002 & 0.247 & 1.586 & 1.654 & 1.610 & 1.628 & 0.125 & 0.187 & 0.052 \\
2003 & 0.273 & 1.670 & 1.750 & 1.699 & 1.719 & 0.139 & 0.207 & 0.052 \\
2004 & 0.310 & 1.803 & 1.900 & 1.836 & 1.864 & 0.159 & 0.236 & 0.053 \\
2005 & 0.298 & 1.755 & 1.847 & 1.785 & 1.815 & 0.152 & 0.226 & 0.052 \\
\hline
\end{tabular}



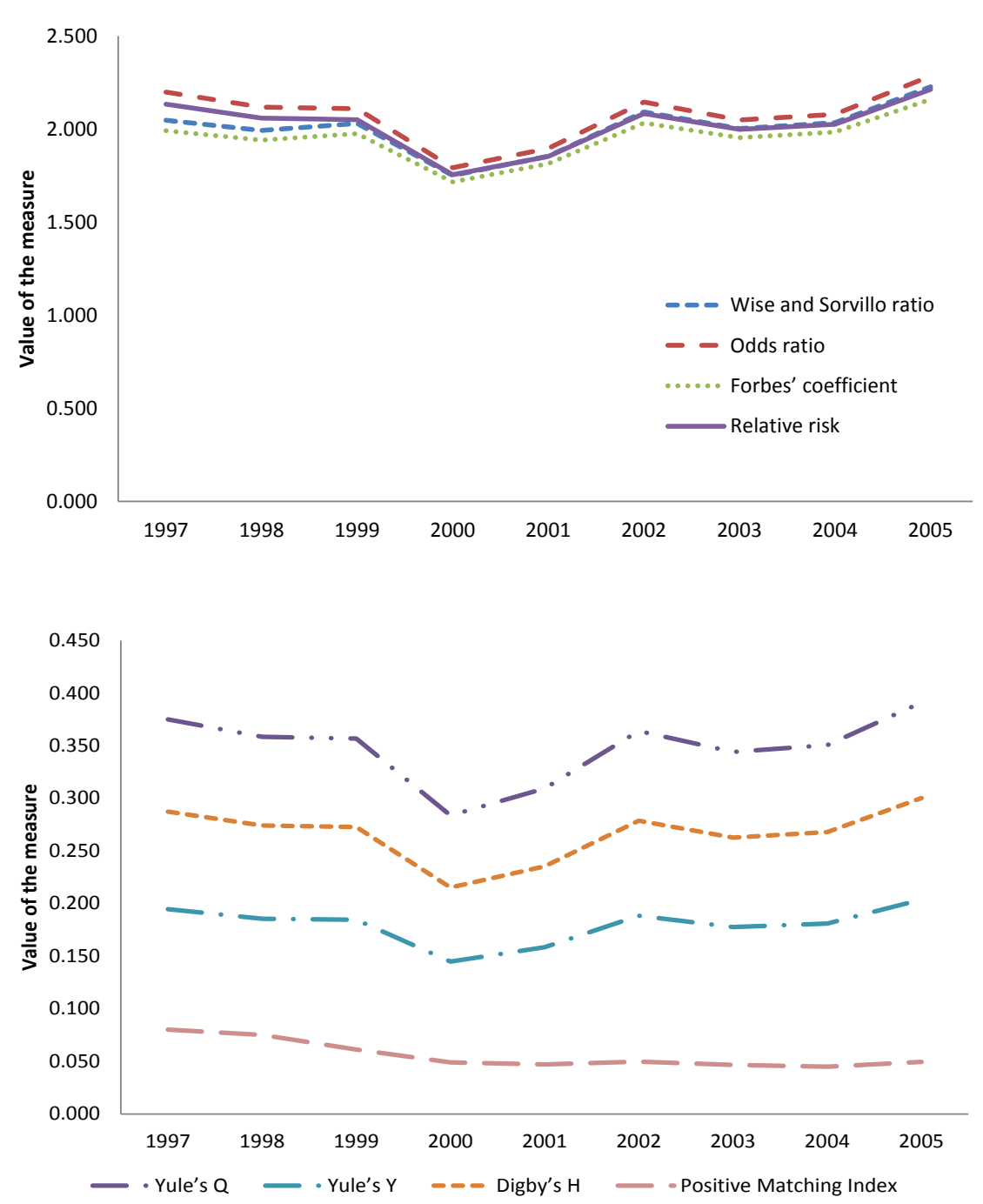

Figures $1 \mathrm{a} \& 1 \mathrm{~b}$. Values of similarity indices for multiple-cause mortality involving diabetes and cardiac arrest, South Africa, males, 1997-2005. 

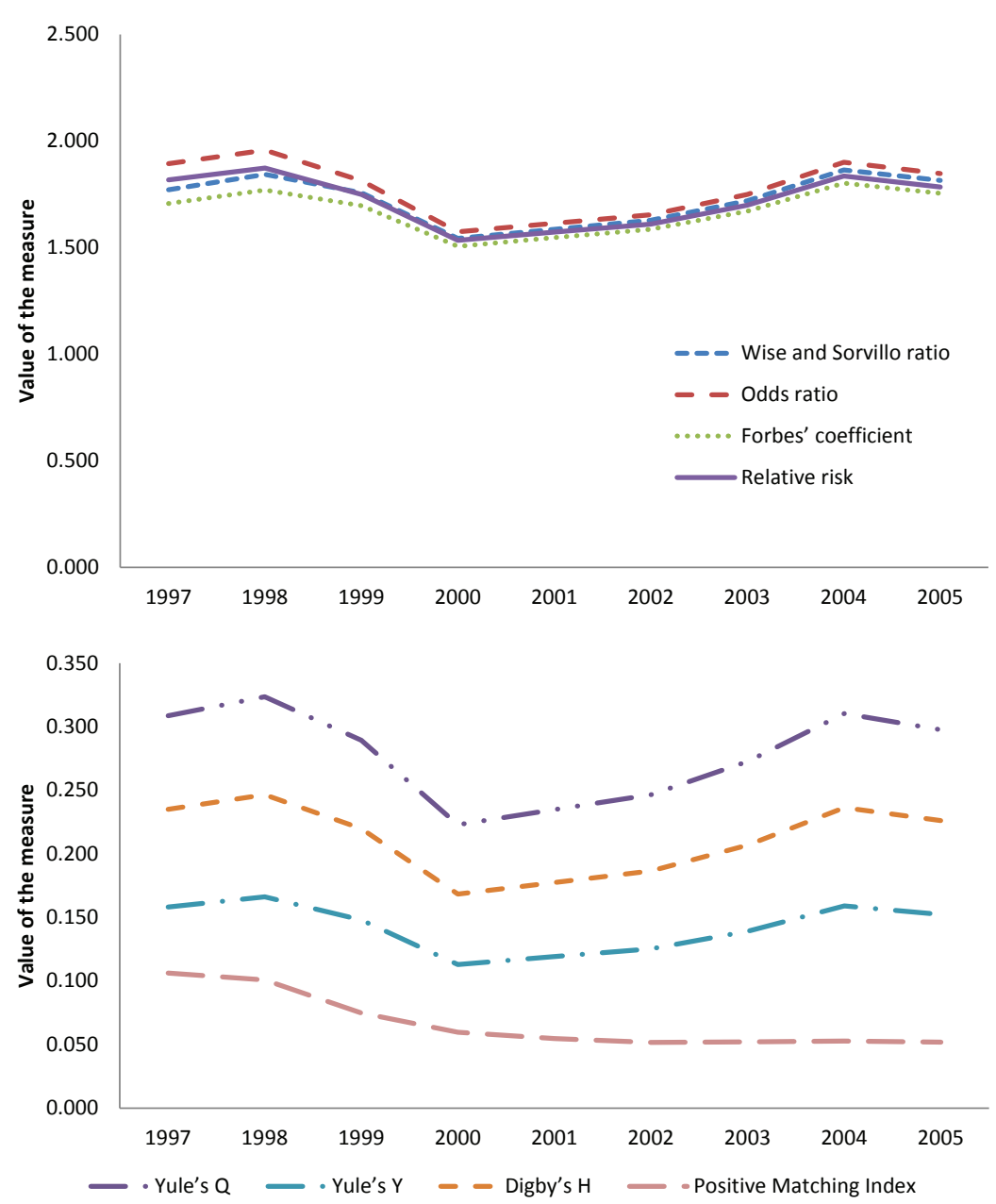

Figure $2 a$ \& $2 b$. Values of similarity indices for multiple-cause mortality involving diabetes and cardiac arrest, South Africa, females, 1997-2005.

\section{Discussion}

The question posed in this paper is whether we need more measures of association for multiple-cause mortality. The corollary to this question is whether the existing measures of association used in multiple-cause mortality are adequate. Our analysis leads us to the answer that existing measures of association for multiple-cause mortality are not adequate enough. The measures fail to satisfy all the theoretical criteria set forth in the paper. These criteria are well established and build upon existing works on measures of association in other fields. When we compare the performance of the measures against actual developments we still find the existing measures to be wanting. It is known that during the 2000s South African mortality increased rapidly. This has mostly been attributed to the increase in deaths due to HIV/AIDS (Bah 2005). What is also known (from this study) is 
that the multiple causes of death due to diabetes and cardiac arrest exhibited two different trends during the study period. Between 1997 and 2000, there was a fairly rapid decrease in the number of cases of deaths due to cardiac arrest, with or without diabetes. Afterwards, the trend remained largely stationary. Of all the different measures used in the study, the-above described pattern was best captured by the PMI, for both males and females. One of the main reasons for this is that the PMI excludes the "non-matches" of no cardiac arrest and no diabetes, and hence is protected from the influence of the rapid increase in those deaths. All the other measures had included "non-matches" and hence exhibited an unrealistic fluctuating trend during the study period.

\section{Conclusion}

This study has shown that the existing measures of multiple-cause association have been found to be inadequate. They do not satisfy all the seven criteria set forth for the qualities of an ideal measure of multiple-cause association. The measures also performed poorly upon application to real multiple-cause data. One of the main reasons for the shortcoming in these existing measures is their inclusion of non-matches. The PMI, on the other hand, fulfilled all the criteria set forth and performed very well on real multiple-cause data. It is recommended that the PMI be used for studies on multiple-cause association based on a $2 \mathrm{x} 2$ matrix of the presence/absence of two co-morbid conditions.

\section{References}

Bah, S. 2005. HIV/AIDS in South Africa in the light of death registration data: In search of elusive estimates, in The Demography of South Africa, edited by T. Zuberi et al., Armonk, NY: M.E. Sharpe, pp. 120-59.

- 2009. Cause_Limp v1.0: A windows-based software for analyzing data on multiple causes of death. Journal of Health Informatics in Developing Countries, 3(2):1-4.

Bah, S., and M. Mahibur Rahman. 2009. Measures of multiple-cause mortality: A synthesis and a notational framework. Genus 65(2):29-43.

Chamblee, R.F. 1982. New dimensions in cause of death statistics. American Journal of Public Health 72:1265-70.

Choi, S., S. Cha, and C.C. Tappert. 2010. A survey of binary similarity and distance measures. Journal of Systemics, Cybernetics, and Informatics 8(1):43-8.

Digby, P.G.N. 1983. Approximating the tetrachoric correlation coefficient. Biometrics 39:753-7.

Dos Santos, D.A., and R. Deutsch. 2010. The Positive Matching Index: A new similarity measure with optimal characteristics. Pattern Recognition Letters (2010), DOI: 10.1016/j. patrec.2010.03.010.

Hayek, L.-A.C. 1994. Analysis of amphibian biodiversity data, in Measuring and Monitoring Biological Diversity: Standard Methods for Amphibians, edited by W. R. Heyer et al. Washington, DC: Smithsonian Institution, pp. 207-69.

Israel, R., H. Rosenberg, and L. Curtin. 1986. Analytical potential for multiple cause-ofdeath data. American Journal of Epidemiology 24:161-79. 
Jougla, E., F. Rossolin, and G. Pavillon. 2008. Cause of death statistics: Production process, quality, and international comparability, in Atlas of Cancer Mortality in Europe, edited by P. Boyle and M. Smans. Lyons: International Agency for Research on Cancer, pp. 1-7.

Mannino, D.M., E. Ford, G.A. Giovino, and M. Thun. 1998. Lung cancer deaths in the United States from 1979 to 1992: An analysis using multiple-cause mortality data. International Journal of Epidemiology 27:159-66.

Sokal, R.R., and P.H. Sneath. 1963. Principles of Numerical Taxonomy. San Francisco: Freeman.

Speizer, F.E., C. Trey, and P. Parker. 1977. The uses of multiple causes of death data to clarify changing patterns of cirrhosis mortality in Massachusetts. American Journal of Public Health 67(4):333-6. DOI: 10.2105/AJPH.67.4.333.

Tan, P., V. Kumar, and J. Srivastava. 2004. Selecting the right objective measure for association analysis. Information Systems 29:293-313.

Tulloss, R.E. 1997. Assessment of similarity indices for undesirable properties, and a new tripartite similarity index based on cost functions, in Mycology in Sustainable Development: Expanding Concepts, Vanishing Borders, edited by M.E. Palm and I.H. Chapela. Boone, NC: Parkway Publishers, pp. 122-43.

Wall, M.M., J. Huang, J. Oswald, and D. McCullen. 2005. Factors contributory with reporting multiple causes of death. Medical Research Methodology 5(4). DOI: 10.1186/1471-2288-5-4.

Warrens, M.J. 2008. On association coefficients for $2 \times 2$ tables and properties that do not depend on the marginal distributions. Psychometrika 73(4):777-89. December 2008 DOI: $10.1007 /$ S11336-008-9070-3.

Wilkins, K., M. Wysocki, C. Morin, and P. Wood. 1997. Multiple causes of death. Health Reports (Statistics Canada) 9:19-29.

Wise, M., and F. Sorvillo. 2005. Hepatitis A-related mortality in California, 1989-2000: Analysis of multiple cause-coded death data. American Journal of Public Health 95:200-5.

Yule, G.U. 1912. On the methods of measuring the association between two attributes. Journal of the Royal Statistical Society 75:579-652. 


\section{Appendix 1}

\section{Summary of reviews of measures of similarity}

In searching for ideal measures of association, a typical approach followed by several authors is to start off with a review or partial review of some existing measures. This is followed by definition of desirable properties of 'good indices' or some criteria for judging 'the best' or 'the ideal' measure of association. The measures are then subjected to these criteria and subsequently, judgments are made on their performance, and in some case, a newer, and supposedly, better index is proposed. Among others, this approach was adopted by Tulloss (1997), Tan, Kumar and Srivastava (2004), Warrens (2008) and Dos Santos and Deutsch (2010). Such approaches are very insightful for several reasons. First, they provide critical reviews of existing measures of association. Second, they allow for comparison of the performance of the different measures. Lastly, they introduce newer measures of association and further push the frontiers of knowledge on measures of association.

Toulloss (1997) reviewed 20 measures of association, giving their definitions and their shortcomings. He set up eight criteria for identifying good measures of similarity. He found that none of the measures satisfied all the criteria and ended up proposing a new index, the Tripartite Similarity Index (TSI) and recommended that the index be used in place of all the 20 indices reviewed.

Tan, Kumar and Srivastava (2004) reviewed 21 measures of association, giving their definitions and ranges. The paper used eight criteria for judging an index of association to be good. None of the 21 measures satisfied all the criteria. Of the 21 measures, the ones that clearly satisfied most of the criteria were Yule's Q and Yule's Y (seven out of eight). The paper made a grouping of the measures according to similarity of properties. Seven groups were identified, with one of them comprising of odds ratio, Yule's Q and Yule's Y.

Warrens (2004) reviewed 15 measures of association categorizing them into five groups. One of the groups contains the odds ratio, Yule's Q, Yule's Y and Digby's H. Warrens set up three criteria that measures of association should exhibit, independent of the data. It happened that only the four measures in the aforementioned group satisfied all the three criteria.

Dos Santos and Deutsch (2010) critically reviewed the TSI index developed by Tulloss (1997). They found the index unsatisfactory and developed a new index of similarity, the Positive Matching Index (PMI) to replace it. They showed that the PMI satisfied all the eight criteria of Tulloss (1997) and performed better than his TSI measure.

The reviews of measures of association and the above-described selected measures are summarized in the Table A1 below: 
Table A1. Summary of reviews of measures of similarity.

\begin{tabular}{|c|c|c|c|}
\hline Source & Indices reviewed & $\begin{array}{l}\text { Recommended } \\
\text { index }\end{array}$ & Reason for choice \\
\hline Toulloss (1997) & $\begin{array}{l}\text { Simpson's coefficient } \\
\text { Second Kulczynski coefficient } \\
\text { Ochiai/Otsuka coefficient } \\
\text { Dice coefficient } \\
\text { Jaccard coefficient } \\
\text { Sokal and Sneath coefficient } \\
\text { First Kulczynski coefficient } \\
\text { Mountford coefficient } \\
\text { Correlation ratio } \\
\text { Braun-Blaquet coefficient } \\
\text { Fager and McGowan coefficient } \\
\text { Savage coefficient } \\
\text { Nonmetric coefficient } \\
\text { McConnaughey coefficient } \\
\text { Johnson coefficient } \\
\text { Tripatite similarity Index }\end{array}$ & $\begin{array}{l}\text { Tripatite } \\
\text { similarity Index } \\
\text { (TSI) }\end{array}$ & $\begin{array}{l}\text { It is the closest to } \\
\text { satisfying the eight } \\
\text { requirements laid out }\end{array}$ \\
\hline Tan et al (2004) & 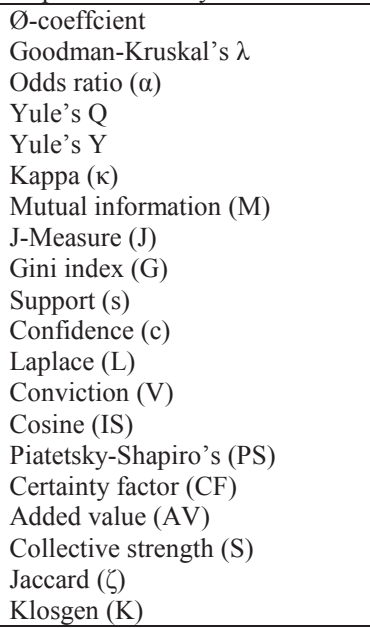 & $\begin{array}{l}\text { Yule's Q } \\
\text { Yule's Y }\end{array}$ & $\begin{array}{l}\text { They satisfy the more } \\
\text { of the seven } \\
\text { properties (six out of } \\
\text { seven) than the other } \\
\text { indices. }\end{array}$ \\
\hline Warrens (2008) & $\begin{array}{l}\text { Odds ratio } \\
\text { Yule's Q } \\
\text { Digby's H } \\
\text { Yule's Y } \\
\text { Jaccard's coefficient } \\
\text { Dice's coefficient } \\
\text { Ochiai's coefficient } \\
\text { Simpson's coefficient } \\
\text { Cole's coefficient } \\
\text { (others not related to the topic of } \\
\text { interest in this paper) }\end{array}$ & $\begin{array}{l}\text { Yule's Q } \\
\text { Yule's Y }\end{array}$ & $\begin{array}{l}\text { They satisfy the three } \\
\text { properties laid out } \\
\text { (desiderata) and can } \\
\text { distinguish between } \\
\text { positive and negative } \\
\text { associations }\end{array}$ \\
\hline $\begin{array}{l}\text { Dos Santos and } \\
\text { Deusah }(2010)\end{array}$ & $\begin{array}{l}\text { Tripatite similarity Index (TSI) } \\
\text { Dice coefficient } \\
\text { Jaccard coefficient } \\
\text { Sorenson coefficient } \\
\text { Positive Matching Index (PMI) }\end{array}$ & $\begin{array}{l}\text { Positive } \\
\text { Matching Index } \\
(\mathrm{PMI})\end{array}$ & $\begin{array}{l}\text { Satisfies all eight } \\
\text { theoretical } \\
\text { requirements of } \\
\text { Toulloss (1997) }\end{array}$ \\
\hline
\end{tabular}

